\title{
AS JUVENTUDES CONTEMPORÂNEAS, A ESCOLA E A CULTURA DIGITAL
}

\author{
Augusto Russini ${ }^{1}$
}

\begin{abstract}
Resumo: Este artigo tem, por objetivo, apresentar uma reflexão sobre o espaço educativo escolar e suas respectivas conexóes com as juventudes contemporâneas. Assim, o estudo contempla dois momentos: primeiramente, uma discussão sobre a contemporaneidade e a escola; posteriormente, uma problematizaçáo dos discursos que a vinculam com as juventudes inseridas na cultura digital. Metodologicamente, trata-se de uma pesquisa bibliográfica e, para tanto, foram consultados autores que discutem a contemporaneidade, a escola, a emergência da cultura digital e as juventudes. A partir das reflexóes, é possível identificar o descompasso entre as juventudes engendradas em um mundo marcado pelo consumo das tecnologias digitais, ou imersa na cultura digital, e a instituiçấo escolar, que mantém suas práticas disciplinadoras erigidas na modernidade. O encontro das juventudes com a escola é, portanto, caracterizado por tensóes, visto que, na maioria das vezes, os saberes extraescolares dos estudantes entram em contradição com o conhecimento escolar, que se apresenta fragmentado e desconectado da realidade vivida pelo jovem contemporâneo.
\end{abstract}

Palavras-chave: Contemporaneidade. Juventudes. Escola. Tecnologias Digitais. Cultura Digital.

\section{CONTEMPORARY YOUTH, SCHOOL, AND DIGITAL CULTURE}

\begin{abstract}
This article aims to present a reflection on the school educational space and its respective connections with contemporary youth. Thus, the study contemplates two moments: first, a discussion about contemporaneity and the school; later, a problematization of the speeches that link it with youth inserted in digital culture. Methodologically, it is a bibliographic research and, for that, authors were consulted who discuss contemporary, the school, the emergence of digital culture, and youth. From the reflections, it is possible to identify the gap between the youths engendered in a world marked by the consumption of digital technologies, or immersed in digital culture, and the school institution, which maintains its disciplinary practices erected in modernity. The encounter of youths with the school is, therefore, characterized by tensions, since, in most cases, students' out-
\end{abstract}

1 Graduação em História pela Universidade Franciscana e Administração pelo Centro Universitário Cidade Verde, mestrado em Ensino de Humanidades e Linguagens pela Universidade Franciscana, doutorando em Educação na Universidade Luterana do Brasil (ULBRA). Professor da Fundação Bradesco Gravataí. E-mail: augustorussini.sm@gmail.com . 
of-school knowledge contradicts school knowledge, which is fragmented and disconnected from the reality experienced by the contemporary youngling.

Keywords: Contemporary. Youth. School. Digital Technologies. Digital Culture.

\section{INTRODUÇÃO}

Faz algum tempo que os gritos são ensurdecedores: a escola tinha que entrar em órbita e, de fato, o impostergável já está acontecendo. [...] enquanto os alunos de hoje vivem fundidos com diversos dispositivos eletrônicos digitais, a escola continua obstinadamente arraigada em seus métodos e linguagens analógicos; isto talvez explique por que os dois não se entendem e as coisas já não funcionam como se esperaria (SIBILIA, 2012, p. 181)

Em sua obra Redes ou Paredes: a escola em tempos de dispersão (2012), Paula Sibilia reflete sobre o contexto atual onde os avanços da comunicação, da informática e da proliferaçáo de conteúdos assentados em uma cultura audiovisual chocam-se com a escola, a qual ainda representa o ideal civilizador que modelava os corpos e as subjetividades desde o início da Modernidade. A partir do encontro entre a escola, as juventudes contemporâneas e a cultura digital, emerge o questionamento que norteará o presente estudo: como a escola, na atualidade, engendra-se no contexto da cultura digital para atender as juventudes? Não se pretende, aqui, encontrar soluçóes para a escola se tornar atrativa, inclusiva ou atender todas as potencialidades das juventudes, mas sim refletir sobre o cenário atual da escola frente às tecnologias digitais e à cultura digital.

Para Bortolazzo (2018, p. 28), naturalizou-se uma variedade de expressões que vinculam tanto as crianças como os jovens às tecnologias, muitas vezes, atribuindolhes rótulos geracionais, tais como "[...] geração digital, geração Facebook, Nativos Digitais, Geração Y, Z, Geração Google, e assim por diante”. Essa aproximação das juventudes com os artefatos tecnológicos é, sem dúvida, uma das características mais marcantes da contemporaneidade, consolidando-se no consumo/utilização de smartphones, tablets, smart tvs, games, entre outros dispositivos tecnológicos que motivam e instigam transformaçôes culturais e pedagógicas.

Russini (2018, p. 17), ao se referir à escola na atualidade, salienta que "[...] em um mundo em que a tecnologia evolui em uma enorme velocidade e proporciona revoluçôes em diferentes campos e espaços, as escolas ficaram atreladas aos seus métodos de ensino do início do século XX”. Como se percebe, vários pesquisadores contemporâneos vêm afirmado que o descompasso entre as juventudes e a escola, na conjuntura atual, é evidente e pode ser percebido por diversos fatores, como, entre outros, o abandono escolar, a distorção entre a idade/série, reprovaçóes, indisciplina, desmotivação. Refletir sobre esse cenário torna-se relevante para compreender os sujeitos e suas identidades na contemporaneidade. Diante desse contexto, a seguir, apresento uma reflexão sobre este cenário, por meio de uma pesquisa bibliográfica, que no entender de Boccato (2006, p. 266), possibilita ao pesquisador encontrar subsídios necessários para atender as expectativas de um determinado estudo "[...] por meio de referenciais teóricos publicados, analisando e discutindo as várias 
contribuiçóes científicas". Assim o estudo apresenta-se dividido em dois subtítulos, a saber: A contemporaneidade e a escola, As juventudes contemporâneas e a cultura digital no espaço escolar.

\section{A CONTEMPORANEIDADE E A ESCOLA}

Para refletir sobre o cenário contemporâneo e a escola, faz-se necessário recorrer à História, perpassando pela modernidade e o surgimento da instituição escolar. A contemporaneidade, em muitas produções acadêmicas e discursos, é identificada pelo conceito 'pós-modernidade', e tentar encontrar uma cronologia linear que explique a passagem da modernidade para a pós-modernidade é enredarse nas malhas que não permitem olhar para as subjetividades dos sujeitos, caindo na armadilha de construir um estudo generalista marcado por uma visão essencialista da história. Por outro lado, ao valorizar o contexto macro, é possível traçar um itinerário para aprofundar as análises sobre a conjuntura social atual e suas relações com a escola, sejam elas de aproximação ou distanciamento.

David Harvey, em sua obra $A$ condição Pós-moderna (1992), apresenta a tese de que a pós-modernidade remonta ao início da década de 1970, devido às inéditas formas de experimentar o tempo e o espaço engendrados em novas formas de acumulação capitalista, as quais produziram inúmeras transformaçóes sociais. A partir dos anos 1970, houve mudanças estruturais no campo político, econômico, social e cultural, tendo como pano de fundo os avanços tecnológicos que permitiram fazer emergir uma nova configuração social, mais dinâmica e, como destaca Bauman (2001), marcada pela liquidez e fluidez. Giddens (1991, p. 09), por sua vez, sinaliza que essa configuração social é decorrente das alteraçóes que foram se constituindo na modernidade, ao mesmo tempo em que chama atenção para o fato de que "[...] estão se tornando mais radicalizadas e universalizadas do que antes". Para Rossato (2001), a modernidade estava alicerçada no distanciamento das concepçóes medievais, que reestruturam a vida social e promoveram o que Giddens (1991, p. 21) identificou como "[...] desencaixe dos sistemas sociais". Esses desencaixes estáo relacionados com as novas concepçóes de tempo e espaço, as quais conectaram o local e o global, encurtaram as distâncias, fomentaram a burocratização do Estado e oportunizaram novas relaçóes econômicas e comerciais, além de trocas culturais.

A modernidade também foi marcada por avanços tecnológicos, sendo uma das suas principais marcas a racionalidade e a crença no progresso. É dentro desta conjuntura que nasce a instituição escolar. Varela e Alvarez-Uria (1992), ao abordarem o surgimento da escola, mencionam uma série de condicionantes que contribuíram para a sua estruturação entre os século XVI e XVIII, tais como: os embates religiosos entre os reformadores católicos e os protestantes, que percebiam os jovens (desde a tenra idade) como essenciais para a manutenção/ perpetuação de seus princípios teológicos; o surgimento de instituiçôes fechadas (colégios, albergues, hospitais, entre outros); a coexistência das infâncias (angelical e nobilíssima dos Príncipes, a infância de qualidade dos filhos dos burgueses e a 
infância rude relacionada às classes populares) e a naturalizaçáo das diferenças entre as classes sociais.

Neste novo e emergente contexto, as infâncias passaram a ser vistas de forma cada vez mais predominante pelo prisma da fragilidade, da imaturidade e da irracionalidade e, portanto, seria necessário protegê-la e corrigi-la. Para atingir essa finalidade, o enclausuramento dos corpos torna-se fundamental, sendo as açốes educativas centradas na disciplinarização. Cabe destacar, também, que, para as classes abastadas, os colégios eram voltados para o enclausuramento moral a fim de formar governantes; já para as classes populares, por sua vez, restava o sequestro dos seus corpos para a domesticação e a obediência, sendo relegados aos hospícios, hospitais e escolas rudes (VARELA; ALVAREZ-URIA, 1992).

Como se percebe, a emergência da escola, na modernidade, se deu no contexto da manutenção da ordem social e do controle dos corpos. Os governos, atentos aos avanços industriais no final do século XIX e início do século XX, passaram a defender a institucionalização da escola obrigatória para o controle social. A escola evitaria, assim, que as classes populares e vistas como perigosas invertessem o status quo e passassem a exercer domínio sobre a burguesia industrial. Ao discutirem o seu papel para o controle social, Varela e Alvarez-Uria (1992, p. 88) afirmam que, juntamente com uma série de dispositivos criados para o controle das classes populares, a escola

[...] tem por finalidade tutelar o operário, moralizá-lo, convertê-lo em honrado produtor, procuram igualmente neutralizar e impedir que a luta social transborde, pondo em perigo a estabilidade política. Não é casual que as intervençóes tendentes a instaurar nas classes trabalhadoras o sentimento de família conjugal coincidam precisamente com a promulgação da obrigatoriedade escolar. [...] O menino, como se tratasse de um capital potencial, deve ser cuidado, protegido e educado para se obter dele mais adiante os máximos benefícios econômicos e sociais. De sua educação, esperam-se os maiores e melhores frutos.

A escola, dessa maneira, tornou-se uma engrenagem fundamental para a consolidação dos interesses governamentais e da burguesia industrial. Essa concepçáo de escola, voltada para o controle social, a longo do século XX, permanece, ganha novas roupagens e passa a constituir o ambiente escolar, delimitando rotinas e comportamentos; segundo Arriada et al. (2012, p. 52):

Estrutura-se uma "cultura escolar" que divide e disciplina o tempo na escola, tendo um papel crucial na implantação de novos métodos didáticos, estabelecimento de programas, adoção de material didático, aqui incluídos os nascentes manuais. Essa nova escola submete professores e alunos a um modelo de educação altamente especializado no controle e disciplinamento de "corpos e espíritos", a regras e ritos; passa a utilizar elementos de controle, como é o caso das chamadas; regras e comportamentos que permanecerão presentes na escola atual.

Essa organização escolar que permanece, em muitos casos, inalterada, está à espera dos jovens contemporâneos. Dessa forma, uma instituição erigida na 
modernidade com o objetivo de fortalecer o Estado por meio do controle social mantém suas práticas quase inalteradas numa sociedade que, agora, é marcada pela lógica neoliberal (de Estado mínimo) e formada por juventudes caracterizadas pelo contato com artefatos tecnológicos e digitais que possibilitam a comunicação em tempo real com qualquer parte do globo, bem como acesso irrestrito a informaçóes e conteúdos interativos.

Quais seriam as marcas da contemporaneidade? Um primeiro ponto a ser mencionado, nesse contexto, refere-se ao distanciamento da concepção de mundo administrável, previsível e sólido da modernidade. Bauman (2001), ao descrever a sociedade contemporânea, vale-se da metáfora da liquidez para demonstrar a volatilidade das relações sociais, muitas vezes marcadas pela individualidade, pela conexão entre tempo e espaço, pela convivência com o diferente, o imediatismo, a fragmentação das certezas e o consumismo.

De agora em diante, as tecnologias digitais, o entretenimento e a mídia desempenham um papel de vanguarda, e sua associação para fins de consumo geram o que Kellner (2006, p. 128) chamou de "cultura do espetáculo". Em seus próprios termos:

$\mathrm{Na}$ sociedade atual, o entretenimento e o espetáculo entraram nos domínios da economia, da política e do cotidiano, de novas e importantes maneiras. As formas contemporâneas de entretenimento, da televisão ao palco, estão incorporando a cultura do espetáculo aos negócios, transformando filmes, televisão, música, teatros e outros domínios da cultura, assim produzindo formas espetaculares no ciberespaço, na multimídia e na realidade virtual.

O conceito de cultura do espetáculo, apresentado por Kellner na primeira década dos anos 2000, permite perceber a existência de um distanciamento temporal da escola em relação à contemporaneidade, quando pensada pelo viés dos artefatos tecnológicos. Ao trazer o conceito de cultura do espetáculo para compreender a sociedade contemporânea e, por conseguinte, as juventudes, Kellner nos ajuda a identificar como estas se engendram em um mundo marcado pelo uso de diversos artefatos tecnológicos e digitais, ou imerso na cultura digital. Nesse cenário, emerge um questionamento: como a escola atua frente às juventudes que vivenciam uma sociedade cada vez mais interligada à cultura digital?

\section{AS JUVENTUDES CONTEMPORÂNEAS E A CULTURA DIGITAL NO ESPAÇO ESCOLAR}

A presença das tecnologias digitais na vida cotidiana está cada vez mais potencializada. Bortolazzo (2018, p. 28), ao descrever sua influência e desdobramento sobre tarefas rotineiras, afirma o seguinte:

As tecnologias digitais operam numa variedade de espaços e dialogam, interagem, intervêm, monitoram, executam e auxiliam muitas das atividades cotidianas. Pagamento de boletos bancários, acesso às notícias e informaçóes, comunicação instantânea entre familiares e também nos ambientes 
profissionais, trabalhos acadêmicos dentre inúmeras outras tarefas têm se apoiado nas facilidades promovidas pelos avanços tecnológicos.

As juventudes, frente às possibilidades que as tecnologias digitais disponibilizam, passam a consumir cada vez mais artefatos tecnológicos, os quais pedagogizam os seus espaços de convivência, desde as relaçôes familiares, sociais, educacionais até aquelas ligadas ao entretenimento. Ao se referir às juventudes, Dayrell (2003, p. 42) afirma que ser jovem não está vinculado apenas ao campo biológico, um estágio para a vida adulta ou uma etapa com fim determinado. Em sua opiniáo, a juventude deve ser compreendida

[...] como parte de um processo mais amplo de constituição de sujeitos, mas que tem especificidades que marcam a vida de cada um. A juventude constitui um momento determinado, mas não se reduz a uma passagem: ela assume uma importância em si mesma. Todo esse processo é influenciado pelo meio social concreto no qual se desenvolve e pela qualidade das trocas que este proporciona. [...] É nesse sentido que enfatizamos a noçáo de juventudes, no plural, para enfatizar a diversidade de modos de ser jovem existentes.

Em sintonia com os estudos de Dayrell (2003), que identificam as juventudes como plurais e decorrentes das relaçóes sociais, Pereira, Lacerda (2012, p. 188) ao se referirem ao conceito de juventude, destacam que este é uma 'construção social', e logo "[...] náo estamos nos referindo a algo linear que possa ser descrito ou discutido a partir de um conjunto idêntico de características. [...] os jovens não constituem uma classe ou grupo social homogêneo". Nesse contexto, Bortolazzo $(2018$, p. 30) evidencia que as juventudes contemporâneas "[...] se encontram inundadas e, não raro, sendo definidas a partir das relaçôes que mantêm com as tecnologias de base digital”. Destarte, as juventudes contemporâneas apresentam-se capitaneadas pelo uso das tecnologias digitais e, logo, engendradas na cultura digital ${ }^{2}$.

Afinal, o que é cultura digital? Antes de apresentar uma definição de cultura digital, torna-se necessário compreender o conceito de cultura. $\mathrm{Na}$ atualidade, o termo 'cultura' sofreu um deslocamento, deixando de ser associada exclusivamente ao campo artístico e à erudição. Paulatinamente, passou a caracterizar fenômenos de diversas áreas, como, por exemplo, na política, nos estudos acadêmicos e no mundo dos negócios. Hall (1997, p. 16), ao mencionar a centralidade da cultura, destaca "[...] seu papel constitutivo, hoje, em todos os aspectos da vida social".

O maior interesse pela cultura, a partir da segunda metade do século XX, é decorrente, de acordo com Du Gay et al. (1997, p. 1), de duas razóes:

A primeira, nós podemos chamá-la de substantiva (está ligada a assuntos de importância empírica), uma vez que ela se refere diretamente à importância

2 Cabe destacar que ao se referir as juventudes imersas na cultura digital, leva-se em consideração a coexistência de diferentes tipos de acesso aos artefatos tecnológicos digitais perpassando por questōes econômicas, culturais, regionais, contudo entende-se que a presença destes artefatos tecnológicos digitas em maior ou menor escala estabelecem relaçóes com os sujeitos contemporâneos, e por conseguinte com as juventudes. 
crescente de práticas culturais e institucionais em cada área de nossas vidas sociais. $\mathrm{O}$ crescimento dos meios de comunicação, novos sistemas e fluxos de informação global, e novas formas visuais de comunicação tem tido - e continua a ter - um profundo impacto nas maneiras que nossas vidas são organizadas e nas formas nas quais nos compreendemos e nos relacionamos com os outros e conosco mesmos. A segunda, nós podemos chamar de "epistemológica", a qual está fundamentalmente relacionada com as questôes do conhecimento.

A partir das proposiçôes de Du Gay et al. (1997), a cultura não pode mais ser compreendida como um reflexo das artes e da erudição, pois abarca todo o tecido social e assume um papel de partícipe na constituiçáo do mundo social. Logo, as atividades que ocorrem socialmente e geram/produzem significados são essencialmente culturais. Esse entendimento de cultura pode ser exemplificado através do clássico texto de Du Gay et al. (1997, p. 5) Praticando estudos culturais: a história do Walkman da Sony, onde os autores, ao estudarem o dispositivo tecnológico Walkman, passaram a identificá-lo como um artefato cultural, devido aos seguintes fatores:

O W. da Sony não é apenas parte da nossa cultura, ele possui uma cultura própria, em torno dele desenvolveu-se um conjunto particular de significados. A própria palavra WALK - MAN invoca uma imagem ou uma ideia - um conceito - do aparelho. Ele pertence a nossa cultura porque constituímos para ele um pequeno mundo de significados, e esse associar o objeto ao significado é o que faz dele um artefato cultural.

Nessa perspectiva, ao atribuir sentido/significado a um dado objeto, é possível estabelecer relaçôes e construir pontes entre o intangível e o real, em outras palavras, materializam-se, através da linguagem, os sentidos e as definiçóes que constituímos deste objeto, tornando-o cultural. Du Gay et al. (1997, p. 6) acrescentam que o walkman da Sony é cultural "[...] porque o constituímos como um objeto significativo. Podemos pensá-lo, imaginá-lo, falar sobre ele. É cultural porque se conecta com um conjunto particular de práticas sociais, específicas de nossa cultura e modo de vida". Considerar o walkman da Sony como um artefato cultural implica, ainda, associá-lo a um determinado público (jovem, esportivo, funcional e urbano) para construir sua identidade, reconhecer o lugar que ocupa nas mais diferentes mídias (outdoors, revistas, propagandas), constituindo linguagens e discursos que o vinculam a uma cultura tecnológica (DU GAY et al., 1997).

Dentro da perspectiva dos Estudos Culturais, Bortolazzo (2018, p. 36) define a cultura digital como "[...] um marcador cultural, uma vez que envolveria tanto os artefatos quanto os sistemas de significação e comunicação que demarcam e distinguem nosso modo de vida contemporâneo". Nessa lógica, a cultura digital pode ser entendida não apenas como todos os significados associados aos artefatos produzidos com tecnologias digitais - o que constitui sua dimensão epistemológica -, mas também como o conjunto de práticas sociais associadas ao uso desses artefatos - o que constitui sua dimensão substantiva. Essas duas dimensões constituem nossas 
vidas contemporaneamente, estabelecendo sentidos, pedagogizando os sujeitos e atuando na constituição de suas subjetividades e identidades.

Em poucos termos, a integração das juventudes contemporâneas com a cultura digital está intrinsicamente relacionada com o uso das tecnologias digitais. Feixa, Fernandez-Planells, Figueras-Maz (2016), no artigo Generación Hashtag. Los movimentos juveniles em la era de la web social, realizam um estudo sobre as geraçôes nascidas a partir da década de 1980, que recebem diversas denominaçôes, tais como geração Millennials, geração internet, $\mathrm{y}$, hashtag, arroba, hiperdigital, apresentando, em comum, a capacidade de utilizar a internet e seus mais amplos recursos, estando conectada de maneira móvel e valendo-se das mais diversas plataformas e redes, tais como Twitter e Facebook. O estudo de Feixa, Fernandez-Planells, FiguerasMaz (2016) reveste-se de importância para as reflexôes aqui propostas na medida em que vai demostrando as transitoriedades que constituem as mais distintas gerações nascidas a partir da década de 1980, todas elas marcadas pelo contínuo uso de artefatos tecnológicos. O pesquisador também demostra como as juventudes imersas na cultura digital utilizam esses artefatos, assumindo um protagonismo em diversos movimentos e reestruturando, em um fluxo contínuo, as estruturas sociais. São estas juventudes que chegam à escola. $\mathrm{O}$ estudante que adentra seus muros passa a vivenciar um processo marcado por incompatibilidades entre os saberes adquiridos em suas vidas extraescolares e os conhecimentos fragmentadas que marcam os conteúdos curriculares (SILVA, 2015).

Por outro lado, não devem ser desconsideradas as inúmeras tratativas para operacionalizar o uso das tecnologias digitais na escola. Sibilia (2012, p. 182) discorre sobre algumas dessas iniciativas, como, por exemplo, a implementação de um computador por aluno em vários países da América Latina. Contudo, também alerta que a tecnologia disponibilizada nos espaços escolares, frequentemente,

[...] é considerada um mero instrumento a ser incorporado às práticas escolares, como se fosse uma ferramenta neutra capaz de atualizá-las [...] nem os computadores nem a internet, nem os telefones celulares são recursos "neutros" como se costuma dizer, cuja eficácia dependeria da utilização que lhes é dada.

Sibilia (2012) também nos adverte de que é justamente na utilização das tecnologias digitais que se descortinam os aparatos de vigilância dentro do ambiente escolar. Legislaçóes, manuais, regimentos que pró́bem ou limitam o uso de celulares, tablets, videogames, entre outros dispositivos tecnológicos, estão associados a discursos naturalizados que os vinculam à falta de atenção e a atitudes de indisciplina, prejudicando a aprendizagem dos estudantes (SIBILIA, 2012). Por essa razão, a pesquisadora acredita que o sucesso do modelo disciplinar da escola para fins de controle social não mais encontra espaço na sociedade informatizada, onde os sujeitos se conectam às redes sem fio em qualquer tempo e espaço. Nessa lógica, a transformação da escola para atender as juventudes contemporâneas é condição sine qua non. 
Outro aspecto a ser destacado nessa discussão é a relação da educação escolarizada com os interesses econômicos, políticos e sociais atuais, os quais, muitas vezes, estão ancorados em discursos salvacionistas cuja principal finalidade é mascarar ou dissimular a lógica do consumo, defendendo, como melhor saída para os 'problemas da educação', a implementação total da tecnologia como a única possibilidade de manter a escola viva. Em algumas versóes desses discursos, chegase, inclusive, a vislumbrar o fim da instituição escolar, que seria substituída por uma educaçáo totalmente mediada por plataformas digitais. Um dos primeiros expoentes do debate sobre o papel das tecnologias na educação foi o professor Seymour Papert, em sua célebre obra $A$ máquina das crianças, publicada originalmente no ano de 1980. Nessa obra, o autor havia destacado a obsolescência da escola frente às tecnologias, mais precisamente, dos computadores, que, interligados em redes, concederiam, às crianças, maior acesso às informaçôes, além da possibilidade de criarem seus próprios meios de aprendizagem, sem depender dos adultos, dos professores e da escola.

Passados mais de trinta anos desde o lançamento da obra de Papert, os avanços tecnológicos digitais proliferam, e a escola permanece com seus métodos de ensino e de aprendizagem ainda calcados em uma lógica de artefatos analógicos. Ao refletir sobre o espaço educativo na cultura digital, Bortolazzo (2018, p. 41) destaca que é necessário pensar o seguinte:

[...] não se requer mais tanto a dependência de recursos fixos tais como computadores, laboratórios de informática, bibliotecas ou mesmo professores. A colaboração e produção coletiva de conteúdo, que acontece em redes sociais, blogs [...] tem permitido olhar para a educação a partir da ótica digital, seja buscando especificidades, seja procurando compreendê-las na relação com as redes sociais. [...] a ampliação das formas de conexão entre homens e homens, máquinas e homens, e máquinas e máquinas, motivadas pelo nomadismo da cultura contemporânea [...] permite que a era da conexão transforme a educação em um processo globalizado, envolvendo o usuário em plena mobilidade.

Para finalizar esta breve discussão, pode-se afirmar que as transformações tecnológicas ocorridas a partir dos anos 1970 foram aceleradas e configuraram uma nova organização social. A escola está engendrada neste contexto e, por essa razão, é necessário refletir sobre suas práticas, seus espaços e métodos de aprendizagem, considerando as experiências extraescolares das juventudes contemporâneas, muitas delas construídas nos ambientes da cultura digital.

\section{CONSIDERAÇÓES FINAIS}

A modernidade foi constituída sob a égide da racionalidade, na crença de administrar o futuro e na burocratização do Estado-nação. É em meio a esse contexto, portanto, que surgem diversas instituiçóes com a intencionalidade de controle social e fortalecimento do poder dos governos, entre as quais emerge a escola, valendo-se de diversos artifícios para atingir seus fins, tais como o enclausuramento, o sequestro dos corpos e a disciplinarização. Tornar os corpos dóceis e obedientes significava, 
naquele contexto, constituir sujeitos que atendessem às expectativas da burguesia industrial.

A modernidade também foi um momento marcado pelo alvorecer tecnológico, o qual, no decurso do tempo, foi sendo potencializado, até que, a partir dos anos 1970, o Ocidente mergulhou numa série de transformaçōes que reestruturam praticamente todos os aspectos da vida em sociedade. As tecnologias digitais assumem, agora, uma posiçáo de vanguarda e passam a interferir diretamente nas relaçóes entre os sujeitos.

A intensidade e a instantaneidade dos avanços tecnológicos digitais, assomadas aos discursos e práticas consumistas da sociedade pós-moderna, tornamse marcas da contemporaneidade, e os jovens, frente às inúmeras oportunidades de conexão, constituem-se em grupos que se identificam por diversos fatores, como roupas, músicas, ideias, comportamentos, itens de consumo, entre outros. Tem-se o cenário da cultura digital, um marcador cultural que pedagogiza, cria novas culturas e permite pensar os jovens de forma múltipla, devido às inúmeras interfaces que os constituem como sujeitos. Assim, a juventude não pode ser entendida no singular, mas no plural.

Essas juventudes contemporâneas estão, cada uma a seu modo, imersas na cultural digital e sendo pedagogizadas pela utilizaçáo dos artefatos tecnológicos digitais. Carregam, consigo, diversos aprendizados e conhecimentos, muitas vezes, desvinculados dos saberes escolares; e, no decurso de suas vidas, adentram os espaços da escola, que ainda está formatada em um viés disciplinador que traz, em seu modus operandi, práticas consolidadas na modernidade.

O encontro das juventudes contemporâneas com a escola não é pacífico, os embates e os tensionamentos proliferam. Muitas inciativas para tornar o espaço escolar atrativo e voltado para o interesse dos públicos juvenis emergem: compramse computadores, tablets, flexibiliza-se o uso de smarthones como uma roupagem; mas o que prepondera nas mentes e coraçóes de muitos educadores continua sendo decorrente da sua formaçáo arquitetada no pensamento moderno.

Muitos estudiosos em educação arriscam soluçóes salvacionistas, as quais, como num passe de mágica, transformariam amplamente a instituição escolar de forma propositiva e inovadora. Contudo, o desenvolvimento tecnológico e digital não cessa, capta a atenção das juventudes e a pedagogiza, e as propostas salvacionistas da escola se esfacelam como se nunca tivessem sido postas em discussão. Caminhos existem, ouvir as juventudes e valorizar seus conhecimentos extraescolares é uma atitude que a escola precisa aprender a implementar em seu ofício, de modo que o espaço da escolarização se torne mais conectado com as juventudes contemporâneas.

\section{REFERÊNCIAS}

ARRIADA, E; et al. A sala de aula no século XIX: disciplina, controle e organização.

Conjectura: Filosofia e Educaçáo. Caxias do Sul, v. 17, n. 2, p. 37-54, maio/ago. 
2102. Disponível em: http://www.ucs.br/etc/revistas/index.php/conjectura/article/ view/1649/1025. Acesso em: 20 nov. 2020.

BAUMAN, Z. Modernidade líquida. Trad. Plínio Dentzien. Rio de Janeiro: Zahar, 2001. BOCCATO, V. R. C. Metodologia da pesquisa científica na área odontológica e o artigo científico como forma de comunicação. Revista de Odontologia da Universidade de Sáo Paulo. Sáo Paulo, v. 18, n. 3, p. 265-274, set./dez. 2006. Disponível em: http://arquivos. cruzeirodosuleducacional.edu.br/principal/old/revista_odontologia/pdf/setembro_ dezembro_2006/metodologia_pesquisa_bibliografica.pdf. Acesso em: 25 nov. 2020.

BORTOLAZZO. S. O lugar da educação na cultura digital: esboço de crianças e jovens digitais. Textura. Canoas, v. 20, n.44, p.27-44, set/dez 2018. Disponível em: http://www. periodicos.ulbra.br/index.php/txra/issue/view/298. Acesso em: 01 set. 2020.

DAYRELL, J. O jovem como sujeito social. Revista Brasileira de Educação. Rio de Janeiro, no 24, p. 24-52, set./out./nov./dez. 2003. Disponível em: http://www.scielo.br/ pdf/rbedu/n24/n24a04.pdf. Acesso em: 15 nov. 2020.

DU GAY, P. et al. Praticando estudos culturais: a história do walkman da Sony. [Trad. Leandro B. Guimarães, Maria C. Braun e Maria Isabel E. Bujes]. London: Sage, 1997.

FEIXA, C; FERNÁNDEZ-PLANELLS, A; FIGUERAS-MAZ, M. Generación Hashtag. Los movimientosjuvenilesenla era de la web social. Revista Latinoamericana de

CienciasSociales, Niñez y Juventud. Mnizales, v. 14, n. 1, p. 107-120, 2016. Disponível em: http://www.scielo.org.co/pdf/rlcs/v14n1/v14n1a07.pdf. Acesso em: 15 nov. 2020.

GIDDENS. A. As consequências da modernidade. São Paulo: UNESP, 1991.

HALL, S. A centralidade da cultura: notas sobre as revoluçóes culturais do nosso tempo.

Educaçáo e Realidade. Porto Alegre, v. 22, n. 2, p. 15 - 46, 1997. Disponível em: https://seer.ufrgs.br/educacaoerealidade/article/view/71361/40514. Acesso em: 14 ago. 2020.

HARVEY, D. A condição pós-moderna. 17. ed. Trad. Adail Ubirajara Sobral; Maria Stela Gonçalves. São Paulo: Loyola, 1992.

KELLNER, D. Cultura da mídia e triunfo do espetáculo. In: MORAES, D. (Org).

Sociedade Midiatizada. Rio de Janeiro: Mauad, 2006, p. 119-147.

ROSSATO, R. Sociologia das origens à pós-modernidade. Santa Maria: Biblos, 2011.

PAPERT, S. M. A máquina das crianças: Repensando a escola na era da informática. Porto Alegre: Artes Médicas, 1994.

PEREIRA, M. V; LACERDA, M.P.C. Juventudes: notas para reflexões. Educação em Foco. Juiz de Fora, v, 16, n. 2, p. 185-206, 2012. Disponível em: https://www.uff.br/ revistaedufoco/files/2012/08/Texto-08.pdf. Acesso em: 25 nov. 2020. 
RUSSINI, A. O ensino de Geografia e História na pós-modernidade: os desafios e as possibilidades das multimodalidades e das tecnologias. 2018, 99 f. Dissertação - Mestrado em Ensino de Humanidades e Linguagens. Universidade Franciscana. Disponível em: http://tede.universidadefranciscana.edu.br:8080/bitstream/UFNBDTD/656/5/Dissertacao_AugustoRussini.pdf. Acesso em: 20 nov. 2020.

SIBILIA. P. Redes ou Paredes: A escola em tempos de dispersáo. Trad. Vera Ribeiro. Rio de Janeiro: Contraponto, 2012.

SILVA, M. P. Juventude (s) e a escola atual: tensóes e conflitos no encontro de culturas. Revista Educaçáo Popular. Uberlândia, v. 14, n. 01, p. 46-59, jan./jun. 2015. Disponível em: http://www.seer.ufu.br/index.php/reveducpop/article/view/28958/pdf. Acesso em: 20 nov. 2020.

VARELA, J.; ALVAREZ-URIA, F. A maquinaria escolar. Teoria e Educação. São Paulo: n. 06, p. 68-96, 1992. 